\title{
Experimental Investigation of Film Cooling Performance for a New Shaped Hole at the Leading Edge
}

\author{
Tarek Elnady $^{*}$ and Ibrahim Hassan ${ }^{\dagger}$
}

\begin{abstract}
An experimental investigation has been performed to study the film cooling performance of a smooth expansion exit at the leading edge of a gas turbine vane. A twodimensional cascade has been employed to measure the cooling performance of the proposed expansion using the transient Thermochromatic Liquid Crystal technique. One row of cylindrical holes, located on the stagnation line, is investigated with two expansion levels, $2 \mathrm{~d}$ and $4 \mathrm{~d}$, in addition to the standard hole. The air is injected at $90^{\circ}$ and $60^{\circ}$ inclination angle relative to the vane surface at four blowing ratios ranging from 1 to 2 at a 0.9 density ratio. The Mach number and the Reynolds number based on the cascade exit velocity and the axial chord are 0.23 and 1.4E5, respectively. The detailed local heat transfer coefficient over both the pressure side and the suction side are presented in addition to the lateral-averaged normalized heat transfer coefficient. The proposed expansion provides a lower heat transfer coefficient compared with the standard cylindrical hole over the investigated blowing ratios. Combining the heat transfer coefficient with the corresponding cooling effectiveness, previously presented, the smooth expansion shows a significant reduction in the heat load with more uniform distribution of the coolant over the leading-edge region. The strong confrontation between the coolant jet and the mainstream, in case of $90^{\circ}$ injection, yields a strong dispersion of the coolant with higher heat transfer coefficient and high thermal load over the vane surface.
\end{abstract}

\section{Nomenclature}

$\mathrm{C}$ true chord $(\mathrm{cm})$

$\mathrm{C}_{\mathrm{p}} \quad$ specific heat capacity $(\mathrm{J} / \mathrm{kg} . \mathrm{K})$

$\mathrm{C}_{\mathrm{x}} \quad$ axial chord $(\mathrm{cm})$

d hole diameter $(\mathrm{mm})$

h heat transfer coefficient with film cooling (W/m.K)

$\mathrm{h}_{\mathrm{o}} \quad$ heat transfer coefficient without film cooling $\left(\mathrm{W} / \mathrm{m}^{2} . \mathrm{K}\right)$

$\mathrm{k}$ thermal conductivity (W/m.K)

1 hole length ( $\mathrm{mm})$

$\mathrm{p} \quad$ pitch (distance between two holes) (mm)

q heat load (W)

$\mathrm{s} \quad$ surface distance downstream the cooling hole $(\mathrm{mm})$

$\mathrm{T}$ temperature $(\mathrm{K})$

$\mathrm{T}_{\mathrm{i}} \quad$ Initial temperature of the surface $(\mathrm{K})$

$\mathrm{T}$ time (second)

v velocity $(\mathrm{m} / \mathrm{s})$

\footnotetext{
* $\quad$ Egyptian Armed Forces, Egypt.

$\dagger$ Department of Mechanical Engineering, Texas A\&M, Qatar.
} 


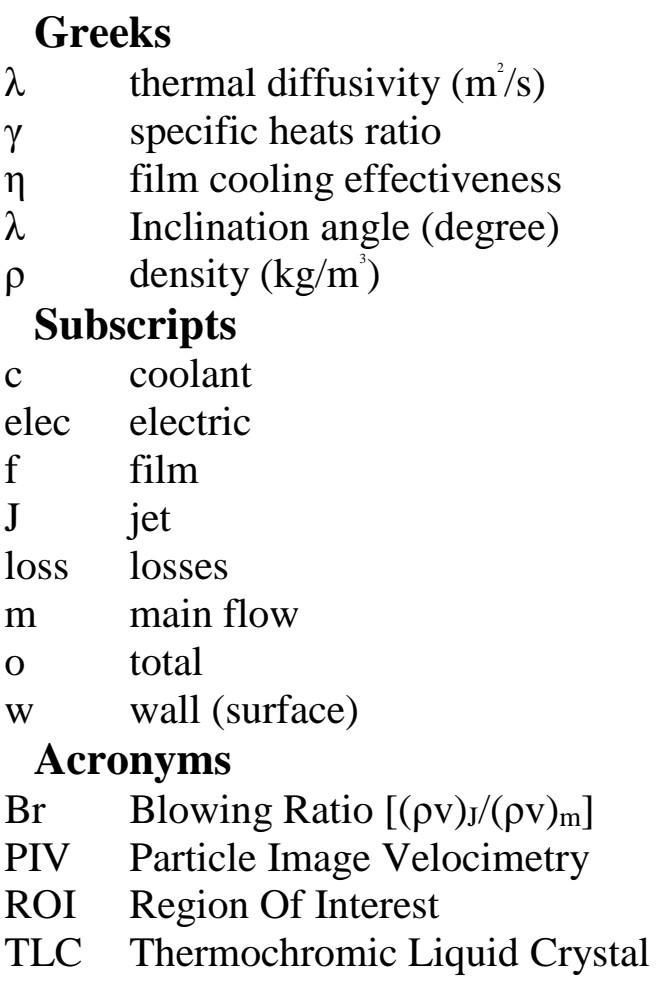

\section{Introduction}

The leading edge is extremely exposed to the hottest flow temperature accompanied with the stagnant nature of the main flow, resulting in the highest heat transfer coefficient over the entire airfoil. The showerhead film hole is introduced to provide more coolant amounts that protect the surface of the leading edge. The highly curved surface at the leading edge invokes sever jet detachment from the surface yielding a strong interaction between the coolant and the mainstream. Therefore, many studies have been conducted to investigate the change in the heat transfer coefficient over the leading edge.

Using the naphthalene sublimation technique to investigate the mass transfer and the heat transfer, Karni and Goldstein [1] varied the injection location relative to the stagnation line using one row injection with both streamwise and spanwise injection. As the injection location moved downstream, the corresponding heat transfer coefficient decreases. The heat transfer coefficient increased and the affected area was increased as well with the blowing ratio increase in the case of the streamwise injection. While the spanwise injection showed more tendency to stable heat transfer coefficient with the blowing ratio. They reported a significant increase in the heat transfer coefficient with the injection at the stagnation line. Using the transient TLC technique, Ekkad et al. [2] investigated the cooling performance of injection near downstream the stagnation line at two different density ratios. They reported a reduction in the heat transfer coefficient at all blowing ratio with the density ratio increase. This finding was matched with the finding of Mick and Mayle [3] for a similar geometry with different injection location downstream the stagnation line using an array of thermocouples.

Simulating the leading edge as a half cylinder, Mehendale and Han [4] experimentally studied the effect of turbulence intensity on the film cooling performance at different blowing ratios. As the mainstream turbulence increased, the flow fluctuations penetrated more through the boundary layer hence the heat transfer coefficient increased. However, the effect of the turbulence reduced with the increase of the blowing ratio due to the severe jet lift-off that leads the coolant away from the surface. The heat transfer coefficient was found to decrease with increasing hole spacing because of less flow interaction and less coverage. Using the same 
model, Ou and Han [5] concluded with the same findings for slot holes. The effect of turbulence intensity was also investigated by Johnston et al. [6] and they found a 30 to 50 percent increase in the baseline heat transfer coefficient with the high turbulence level.

Investigating the effect of zero and off-design incidence, Hoffs et al. [7] measured the cooling performance of the showerhead with three-row and four-row configurations over a cylindrical model using the TLC technique. The four-row configuration showed significant increase in the heat transfer coefficient compared with the three-row. Changing the incident angle caused a significant increase in the heat transfer coefficient particularly at the higher blowing ratio.

The standard cylindrical hole is not enough to provide the required cooling capacity at this region due to the sever jet lift-off and the highly curved surface. Introducing shaped holes over a flat plate, Gritsch et al. [8], Bell et al. [9], Cho et al. [10], and Yu et al. [11] investigated the effect of the film hole exit shape on the interaction between the coolant and the mainstream. In their studies, they concluded an increase in the cooling effectiveness with the shaped holes accompanied by a reduction in the heat transfer coefficient compared with the standard cylindrical hole. Using the transient TLC technique, Reiss and Bolcs [12] measured the cooling performance of three cooling hole shapes on the showerhead region at two Mach numbers. They reported a decrease in the effectiveness by increasing the Mach number due to the thinner boundary layer associated with the high velocity mainstream. The jet then has more of a tendency to penetrate through the thinner boundary layer with different penetration degrees for each exit shape. With a more expanded exit, the strength of the jet to penetrate decreases and the effect of Mach number becomes insignificant.

Modeling the leading edge as an elliptic surface, York and Leylek [13] numerically investigated the cooling performance of standard cylindrical hole and diffused shaped hole at the stagnation line and four diameter distance downstream the stagnation line. In both locations there was a heat transfer coefficient augmentation increase with the blowing ratio due to the corresponding increase in the flow interaction, particularly for the confronting flows. The turbulence intensity of the mainstream and the jet supported the increase in the heat transfer coefficient due to the additional mixing between both streams. Lu et al. [14] studied the effect of the hole angle and shaping on the cooling performance of turbine blade showerhead film cooling using a blunt body model. Higher blowing ratios resulted in a lower increase in the heat transfer coefficient, as the jet lift-off caused less mixing between both streams, and hence less turbulence. The effect of the blowing ratio variation was small compared to the effect of the injection itself. The heat transfer coefficient was also enhanced with the shaping of the hole, however this enhancement was not significant compared to the gained effectiveness, resulting in a lower heat flux reduction ratio.

Islami et al. [15] numerically investigated seven different film cooling holes at the leading edge with two rows, one on the pressure side and the other on the suction side. They found the coolant trace on the suction side was much longer with lower effectiveness than that on the pressure side. The sidewall boundary layer of the hole passage arose a pair of kidney vortices that pushed the coolant upward and pulled the hot gases towards the surface yielding to jet lift-off. The convex surface produced a favorable pressure gradient that allowed the coolant to reattach close to the surface far downstream yielded to a long trace. On the pressure side, the pressure difference between the far-field cross-flow and the lowered pressure in the wake downstream the trailing edge of the hole yielded a strong reverse flow just downstream of the hole. This reverse flow acted as a cross-flow, causing an anti-kidney vortices pair. This anti-vortex pair located underneath the jet near to the surface and tends to suppress the jet vertical velocity at the centerline and near downstream the hole edge, therefore further jet lift-off was prevented on the pressure side. The concave surface of the pressure side caused a flow separation due to 
the adverse pressure gradient, yielding to a shorter trace. Shaping the hole exit generally increased the cooling effectiveness with different mechanisms according to the shape geometry. The cylindrical hole with the trench increased the strength of the vortices with tendency to laterally spread rather than vertically penetration especially on the suction side. Diffusing the hole exit reduced the jet velocity in addition to reducing the strength of the formed vortices yielding overall enhancement on the effectiveness on both the pressure and the suction sides. The conical hole caused a spread in both streamwise and spanwise directions, yielding an effectiveness enhancement on both sides.

The leading edge counters the highest heat transfer coefficient through the entire airfoil due to the stagnant nature of the mainstream. The mainstream has a low momentum at the stagnant line followed by high flow acceleration with a thin boundary layer. Because of the significant jet lift-off, the standard cylindrical film holes provide insufficient cooling capacity to protect the leading edge from the high thermal load. Therefore, the leading edge needs a high film cooling density to provide the proper cooling capacity. The previous studies investigated the diffused shaped hole to increase the cooling effectiveness and decrease the heat transfer coefficient; however, the total heat load reduced is still insignificant Lu et al. [14]. In this study, a smooth expansion at the exit of the standard cylindrical hole has been proposed to modify the diffused hole in order to decrease the jet momentum by increasing the area ratio. One row with 10 holes at a radial compound angle is located at the stagnation line of a gas turbine vane on a two-dimensional airfoil cascade. Two steep surface inclination angles, $90^{\circ}$ and $60^{\circ}$ were investigated with two expansion levels, $2 \mathrm{~d}$ and $4 \mathrm{~d}$ in addition to the standard cylindrical hole.

\section{Experimental Setup}

\section{Test Facility and Test Section}

A wind tunnel was established at Concordia University to investigate the film cooling performance in gas turbines. The test facility consists of both mechanical and electronic systems, and is well documented in a companion paper, Elnady et al. [16]. A two-dimensional airfoil cascade, presented in Figure 1, provides similar flow passages that match the physical curved surface and the pressure distribution around a scaled vane used in a typical industrial power generation plant. An adaptor of $27.5 \mathrm{~cm}$ by $12 \mathrm{~cm}$ inlet cross sectional area is installed on the main flow line, upstream of the cascade, to reduce the tunnel cross section area to $9.5 \mathrm{~cm}$ by $5.1 \mathrm{~cm}$. A duct of the same cross section and $150 \mathrm{~cm}$ length is used to convey a fully developed mainstream to the airfoil test sections. While the main stream is kept at room temperature, a heater with a maximum capacity of $1.2 \mathrm{~kW}$ was assembled on the secondary line to heat up the jet before being delivered to the test section. A small plenum of $7 \mathrm{~cm} \times 2 \mathrm{~cm} \times 2 \mathrm{~cm}$ internal dimension is assembled at the bottom of the base part of the test section to feed the airfoil with the secondary flow. Fast acting 3-way solenoid valves route the secondary flow through bypass until steady state conditions are achieved. A thermocouple and a pressure sensor are inserted in the plenum to record the static temperature and pressure of the jet before it is delivered to the airfoil.

The mainstream air is supplied with a volume flow rate of up to $0.5 \mathrm{~m}^{3} / \mathrm{s}$. An additional honeycomb mesh, $5 \mathrm{~cm}$ long with a cell size of $0.6 \mathrm{~cm}$, is placed $180 \mathrm{~cm}$ upstream the vane leading edge to ensure uniform flow. The trailing edge tailboards were contoured to ensure identical streamline flow downstream the vane. The cascade inlet and exit velocities are set to be $34 \mathrm{~m} / \mathrm{s}$ and $90 \mathrm{~m} / \mathrm{s}$ corresponding to Mach numbers 0.1 and 0.23 , respectively. The turbulent intensity was measured using PIV technique one chord upstream the vane leading edge and it was found to be $8.5 \%$. The exit Reynolds number based on the axial chord is 200,000 and the vane pressure ratio $\left(\mathrm{P}_{\mathrm{o}} / \mathrm{P}\right)$ is 1.12 . 


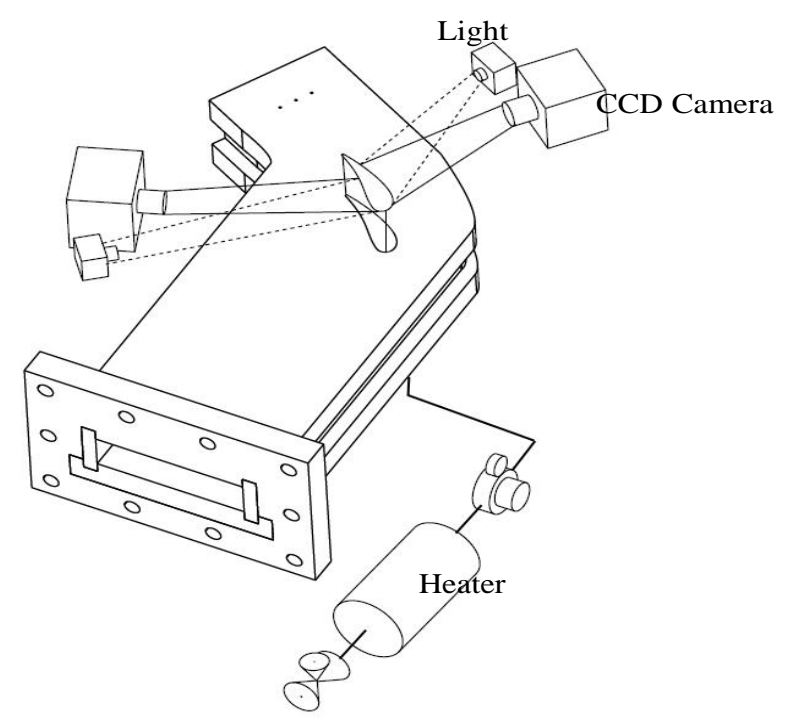

Figure 1. Vane cascade

\section{Hole Geometry and the Test Vane}

Figure 2 shows the proposed smooth expansion at two inclination angles, $90^{\circ}$ and $60^{\circ}$ relative to the vane surface. Two levels of expansion are investigated, $2 \mathrm{~d}$ and $4 \mathrm{~d}$, in addition to the standard cylindrical exit. Only one row, with 10 holes, has been employed on the stagnation line to examine the performance of the aforementioned geometries. A different vane is used for each different hole arrangement thus a total of 6 vanes are employed with four different blowing ratios $(1,1.35,1.7$, and 2$)$. The spanwise spacing of the holes in all cases is $4.5 \mathrm{~d}$, all geometrical details of cooling holes are tabulated in Table 1.

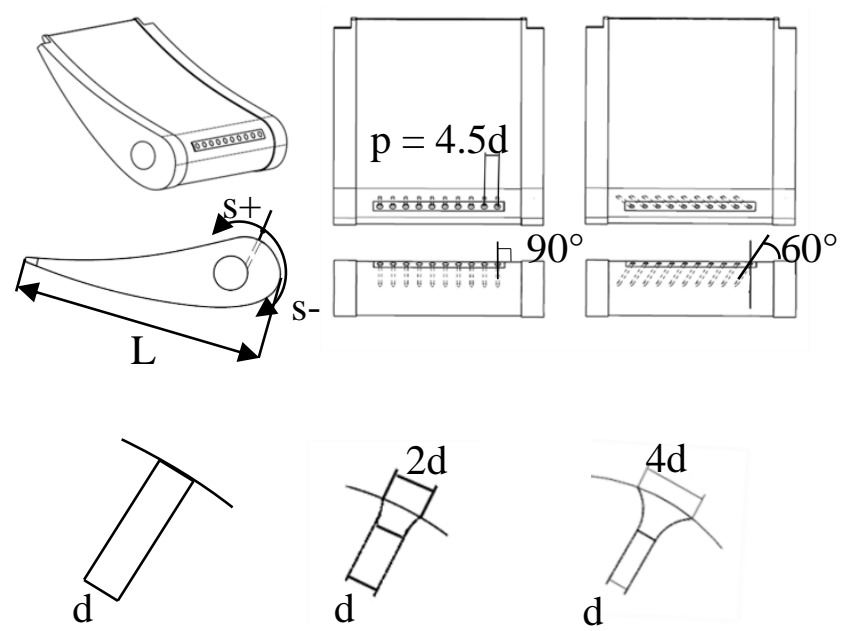

Figure 2. Geometrical aspects of the smooth expansion exit

Each vane is manufactured with a groove of $0.254 \mathrm{~mm}$ depth downstream of the cooling hole. This depth is equal to the TLC sheet thickness to allow the mapping of the temperature distribution over the vane surface without disturbing the development of the boundary layer. A uniform rectangular grid of $5 \mathrm{~mm}$ spacing is drawn on the vane surface to account for the highly curved surface at the vane leading edge. The x-distances between grid lines are measured as a 
number of pixels at different locations along the vane surface and correlated to the actual linear distance. A Thermochromatic Liquid Crystal technique (TLC) is used to map the temperature distribution along the investigated area. A special vane is designed for performing the in-site TLC calibration process to account for the curvature effect. The calibration vane is manufactured with a special groove of $5 \mathrm{~cm} \times 5 \mathrm{~cm} \times 0.36 \mathrm{~mm}$ to contain both the heater and the TLC sheet. The heater (Omega, KH608/205P), with a maximum power output of $0.8 \mathrm{~W} / \mathrm{cm}^{2}$, is used to apply a uniform heat flux to the TLC sheet in the calibration process to achieve the same illumination and camera settings for both calibration and experimental running processes. The heater is fed through a DC regulator (BK PRECISION 1623A) to ensure infinitesimal power steps.

Table 1: Cooling hole arrangement

\begin{tabular}{l|c}
\hline \hline angle to the stagnation line & 0 \\
\hline orientation angle (compound) & $90^{\circ}$ radial \\
\hline Hole angle (deg.) & $90^{\circ}, 60^{\circ}$ \\
\hline No. of holes & 10 \\
\hline Spacing (p/d) & 4.5 \\
\hline \hline
\end{tabular}

A set of colored images is captured at different power inputs so that a steady state temperature reading is achieved after each power step. Each image has a different color map while the surface temperature is recorded using two thermocouples at two different positions. An in-house Matlab code has been developed to perform the image processing for the different TLC colors and transform them to the corresponding hue values. The camera view angle and the light distribution are changed over the vane curved surface. Therefore, each image is divided into small regions, called the Region of Interest (ROI) with a dimension of 1 pixel by 1 pixel. Each ROI has its own hue value and it is related to the surface temperature. The colored images in the experimental measurement are also divided in the same manner. Using an interpolation process, the hue values of the measurement images are interpreted to the corresponding surface temperature.

\section{Data Reduction}

The one-dimensional transient heat conduction through a semi-infinite solid is assumed to determine the local heat transfer coefficient and cooling effectiveness. The unsteady heat conduction equation for one dimensional heat conduction into a semi-infinite solid is given as:

$\rho C_{p} \frac{\partial T}{\partial t}=\frac{\partial}{\partial x}\left(k \frac{\partial T}{\partial x}\right)$

with the initial and boundary conditions

$$
\left.\begin{array}{ll}
\text { @ }=0, & \mathrm{~T}=\mathrm{T}_{\mathrm{i}}, \\
\text { @ } & \mathrm{x}=0 \quad h\left(T_{w}-T_{f}\right)=-k \frac{\partial T}{\partial x} \\
\mathrm{x}=\infty & \mathrm{T}=\mathrm{T}_{\mathrm{i}}
\end{array}\right\}
$$

the solution for Equation (1) was found to be:

$$
\frac{T_{w}-T_{i}}{T_{f}-T_{i}}=1-\exp \left(\frac{h^{2} \alpha t}{k^{2}}\right) \operatorname{erfc}\left(\frac{h \sqrt{\alpha t}}{k}\right)
$$


The initial temperature, $T_{i}$, of the surface as well as the mainstream temperature, $T_{m}$, will be measured by using a thermocouple. The film temperature, $T_{f}$, can be calculated as a function of coolant temperature, $\mathrm{T}_{\mathrm{c}}$, mean temperature, and film cooling effectiveness as follows

$\eta=\frac{\left(T_{f}-T_{m}\right)}{\left(T_{j}-T_{m}\right)}$

Equations (3) \& (4) have three unknowns, $h, \eta$, and $\mathrm{T}_{\mathrm{f}}$. A third equation is needed in order to find a unique solution. Based on the fact that the flow dynamics, rather than the thermal conditions, are the dominant factors that control the turbulent convection, Vedula and Metzegar [17] introduced a solution by performing two different transient tests, using two different injection temperatures, under the same flow conditions.

Due to the higher uncertainty in performing two separate tests with the same flow conditions, Ekkad et al. [18] presented the film cooling performance using a single transient test with an infrared camera. The same methodology is employed in this study with some modifications adapted to the test facility and the measurement method. Equations (3) \& (4) are solved together to eliminate the film temperature, $\mathrm{Tf}$, and both equations are then reduced to one equation in two variables, $h$ and $\eta$.

$T_{w}-T_{i}=\left[1-\exp \left(\frac{h^{2} \bar{\alpha} t}{k^{2}}\right) \operatorname{erfc}\left(\frac{h \sqrt{\bar{\alpha} t}}{k}\right)\right] *\left[\eta\left(T_{j}-T_{m}\right)+T_{m}-T_{i}\right]$

where, $\alpha$ and $\mathrm{k}$ are the thermal diffusivity and the thermal conductivity of the surface material, respectively. Equation (5) is solved using the least square regression method through the 300 images. Each image represents the wall temperature at a certain time step in the transient experiment, to obtain the local $\mathrm{h}$ and $\eta$ for each ROI.

In Equation (5), $\mathrm{Tw}, \mathrm{Tj}$ and $\mathrm{Tm}$ are changing with time during the transient test. The variation of these parameters can significantly alter the solution to the differential equation. However, due to the experimental limitations, noticeable changes have been observed in their values during the running times. Many modifications and technical investigations have been performed to minimize the variation in these values. The change in the jet temperature is the major source of error in this measurement. Decreasing the plenum volume and increasing the tubing insulation provided a significant reduction in the heat loss; however, this could not eliminate the heat loss completely. Another source of error is the conduction effect on the surface in the region around the hole exit. The heat is transferred from the plenum to the area under investigation through a thin wall. An additional material was added to the plenum to increase the wall thickness in order to minimize the heat conduction. Moreover, the mainstream temperature shows a slight decrease during each test of approximately $0.5^{\circ} \mathrm{C}$.

A single transient test of 60 seconds, with a total of 300 images $(\mathrm{N})$ is considered in the present study to solve Equation (5) and calculate the two unknown variables, $\mathrm{h}$ and $\eta$, using a nonlinear least square regression method for each ROI over the target surface. The regression analysis technique reduces the experimental error by considering the infinitesimal changes in each parameter during the fitting process. The surface temperatures of each ROI over the target surface are measured using TLC at each time step $(\tau)$ during transient measurements as,

$\left.\mathrm{T}_{\mathrm{w}(\mathrm{ROI})}(\mathrm{h}, \eta)\right|_{t=\tau}=\left.T_{T L C}\right|_{t=\tau}$ 
In the first few images (n), there was no TLC response over the entire target area. As a result, $\mathrm{N}$-n equations are applied in Equation (5) to calculate the two parameters ( $h$ and $\eta$ ) using nonlinear least square regression method. The optimum solution is achieved by minimizing the least square error $(\varepsilon)$ for each ROI downstream of the film cooling surface as follows:

$\varepsilon(h, \eta)=\frac{1}{2} \sum_{i=n}^{N}\left(\left.T_{w(R O I)}(h, \eta)\right|_{t=\tau}-\left.T_{T L C}\right|_{t=\tau}\right)^{2}$

The number of unused images (n) had an effect on the final solution of $h$ and $\eta$. The " $n$ " is dependent on the time response of the secondary flow over the downstream TLC surface. Each ROI, over the surface, had a different value of $n$, based on the flow conditions. For each ROI, a logical loop is applied to determine the proper number of images (n) that can be selected to provide the minimum least square error $(\varepsilon)$ in Equation (7). The best fit is achieved when the summation of squared residuals had a minimum value.

Each airfoil profile has its own streamline which affects the heat transfer over its surface. In addition, the same airfoil itself has different streamline expansions on both its pressure and suction sides. Therefore, the best way to present the heat transfer coefficient changes on the airfoil surface is by normalizing the heat transfer coefficient of film cooling $\left(\mathrm{h}_{\mathrm{f}}\right)$ to the heat transfer coefficient without film cooling $\left(h_{0}\right)$. The special vane, contains a groove, can be used for measuring the heat transfer coefficient without film cooling over the vane surface. That groove was designed such that its depth contains an electric heater coated with the TLC material without affecting the aerodynamic flow around the vane surface. The mainstream flows over the vane and a constant heat flux is applied using the electric heater. After achieving steady state, an image of the vane is captured with the corresponding temperature contours over the TLC material. The heat transfer coefficient without film cooling can be obtained by applying Equation 8.

$h_{o}=q /\left(T_{w}-T_{m}\right)$

The conduction loss from the heater to the vane surface is calculated based on the thermal conductivity and the constant heat flux boundary condition and it is assumed to be $10 \%$ from the total heat applied by the heater. The electric loss in the wiring is assumed to be $4 \%$ based on the used current, voltage and the wiring cross sectional area. In addition, the radiation loss is assumed to be $(1 \%)$. The heat losses $\left(\mathrm{q}_{\text {loss }}\right)$ in terms of conduction, electric, and radiation losses are estimated to be fifteen percent of the total heat load applied by the heater ( $\mathrm{q}_{\text {elec }}$ ), hence

$\mathrm{q}=\mathrm{q}_{\text {elec }}-\mathrm{q}$ loss, or $\mathrm{q}=0.85$ qelec

The vane is manufactured using a Stereo lithography technique (SLA) from a material with a commercial brand called WaterShed. The thermal properties of this material are not tabulated on the standard heat transfer tables and were needed to be measured by the authors. Therefore, the measurements of the thermal capacitance, the thermal conductivity, and the thermal diffusivity have been performed and their values found to be, with the given uncertainty, $0.211328 \pm 0.0129 \mathrm{~W} / \mathrm{m} . \mathrm{K}$, and $0.127 \mathrm{E}-6 \pm 0.1 \mathrm{E}-7 \mathrm{~m}^{2} / \mathrm{s}$, respectively. Uncertainty analysis is based on 95 percent confidence levels, and determined using procedure described by Kline and McClintock [19] and by Moffat [20]. Mach number uncertainty is 0.002 , temperature is $\pm 0.2^{\circ} \mathrm{C}$, pressure is $\pm 0.2 \mathrm{kPa}$, and the spatial resolution with TLC imaging is $0.1 \mathrm{~mm}$. The uncertainty in determining the exact locations of the thermocouples with respect to local position of each pixel in the calibration process is $0.4^{\circ} \mathrm{C}$. These uncertainty leads to \pm 0.018 in adiabatic effectiveness, about \pm 9 percent for a nominal effectiveness of 0.2. The uncertainty in heat transfer coefficient is found to be $33 \mathrm{~W} / \mathrm{m}^{2} . \mathrm{K}$, about \pm 11 percent of averaged span-wise heat transfer coefficient value of $300 \mathrm{~W} / \mathrm{m}^{2} . \mathrm{K}$ 


\section{Results and Discussion}

The proposed smooth expansion has been examined with different geometrical aspects in order to reduce the interaction between the coolant jet and the mainstream on the leading edge region. One row of holes is employed on the stagnation line of the scaled vane with a radial compound angle. The holes have a $60^{\circ}$ inclination angle to the mainstream direction in addition to a similar row of holes has $90^{\circ}$ inclination angles. The cooling performance of the proposed exit has been measured and compared with the performance of the standard cylindrical hole of the same base diameter at four different blowing ratios 1, 1.35, 1.7, and 2. The mass flow of the coolant delivered to the cylindrical hole for a given blowing ratio was measured at the plenum condition. The measured coolant mass flow is delivered to the proposed exits to compare between all geometries based on the same coolant flow rate. The camera is positioned such that it views the leading edge from the pressure side. Therefore, the measurements are recorded for a distance equal to $12 \mathrm{~s} / \mathrm{d}$ on the pressure side, while the measurements are available only for 8 $\mathrm{x} / \mathrm{d}$ on the suction side due to the high curvature of its surface.

\section{Heat Transfer Coefficient Measurement}

Equation 5 is solved using the least square regression method to obtain both the effectiveness and the heat transfer coefficient. Figure 3 presents the local distribution of the heat transfer coefficient downstream the two expansion levels in addition to the cylindrical hole. The changes in the heat transfer coefficient towards both the pressure side and suction side are presented at four different blowing ratios. With the cylindrical injection, the suction side shows higher heat transfer coefficient compared with that of the pressure side. By employing the first expansion level, $2 \mathrm{~d}$, the heat transfer coefficient on the suction side slightly decreases accompanied by a decrease in the HTC on the pressure side.

However, at high blowing ratio, the jet momentum is still strong enough to penetrate strongly through the main stream causing similar HTC to that with cylindrical exit. Applying the highest expansion level, a noticeable reduction in the heat transfer coefficient has been obtained in both suction and pressure side, even with the highest blowing ratio. The proposed expansion geometry causes a reduction on the heat transfer coefficient downstream the hole on both sides, particularly on the suction side.

The film cooling heat transfer coefficient is normalized by dividing it over the heat transfer coefficient without film cooling. Figure 4 shows the normalized lateral-averaged heat transfer coefficient over the pressure side for the three expansion levels: standard cylindrical, $2 \mathrm{~d}$, and $4 \mathrm{~d}$ at $\mathrm{Br}=1$. Each expansion level is presented at two-hole inclination angles, $90^{\circ}$ and $60^{\circ}$, and the normalized heat transfer coefficient of the York and Leylek [13] is presented as well. The hole in their study was standard cylindrical inclined $20^{\circ}$ with respect to the vane surface. The heat transfer coefficient was lower than that of the present study as the inclination angle in their study was shallower than that of the present study. As the inclination angle is smoother, the major momentum component of the jet is in the direction of the mainstream. Hence, the interaction between the jet and the main flow is then reduced causing the reduction of the heat transfer coefficient.

By increasing the expansion level to $2 \mathrm{~d}$, there are some vortices that are formed due to the short expansion length hence a slight increase in the heat transfer coefficient is observed. At the highest expansion level, $4 \mathrm{~d}$, the coolant is expanded in the longer smooth portion of the hole and yields to the main flow causing a noticeable reduction in the heat transfer coefficient. As the inclination angle changes from $60^{\circ}$ to $90^{\circ}$, the disturbance caused by the jet increases due to the decrease of the momentum component that yields the mainstream, such that all the momentum confronts the main flow, hence the heat transfer coefficient increases. The expansion level changes have insignificant effect on the heat transfer coefficient due to the complete confrontation between both streams in all cases. 

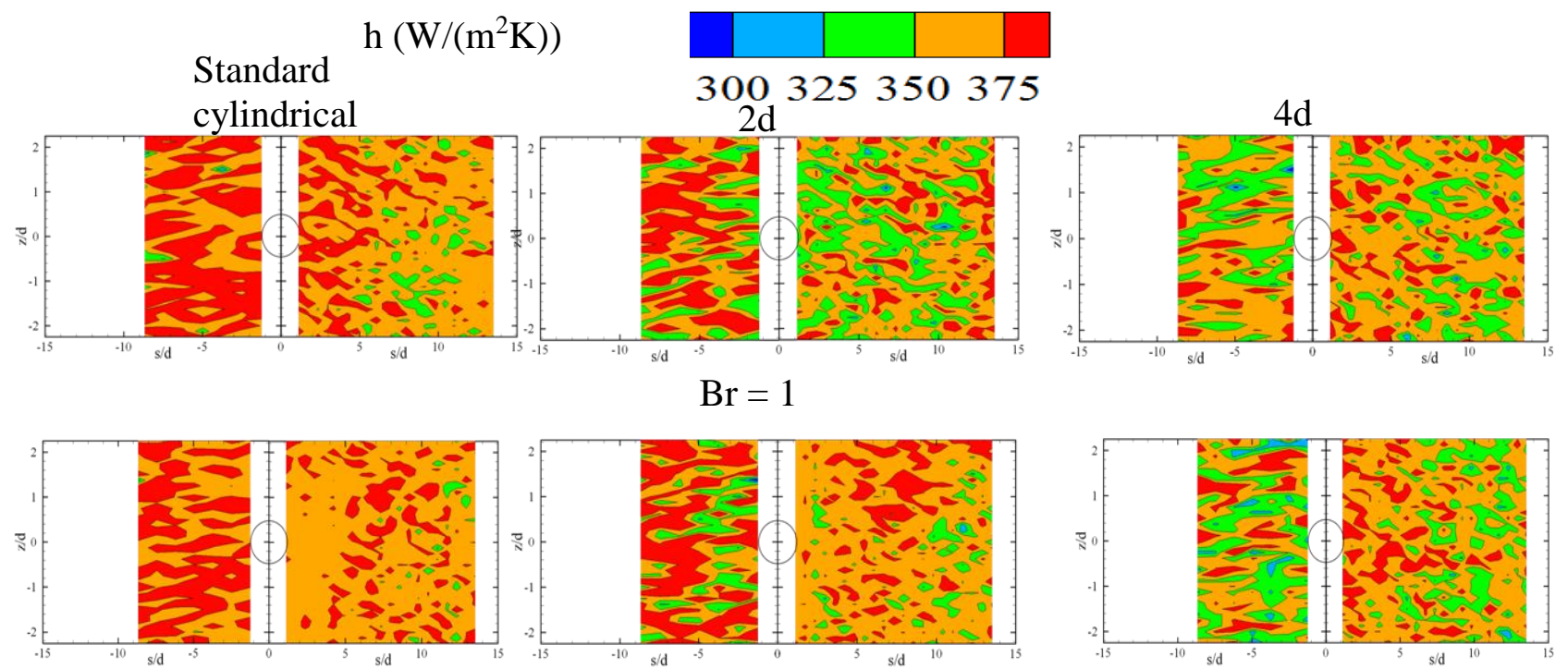

$$
\mathrm{Br}=1.35
$$
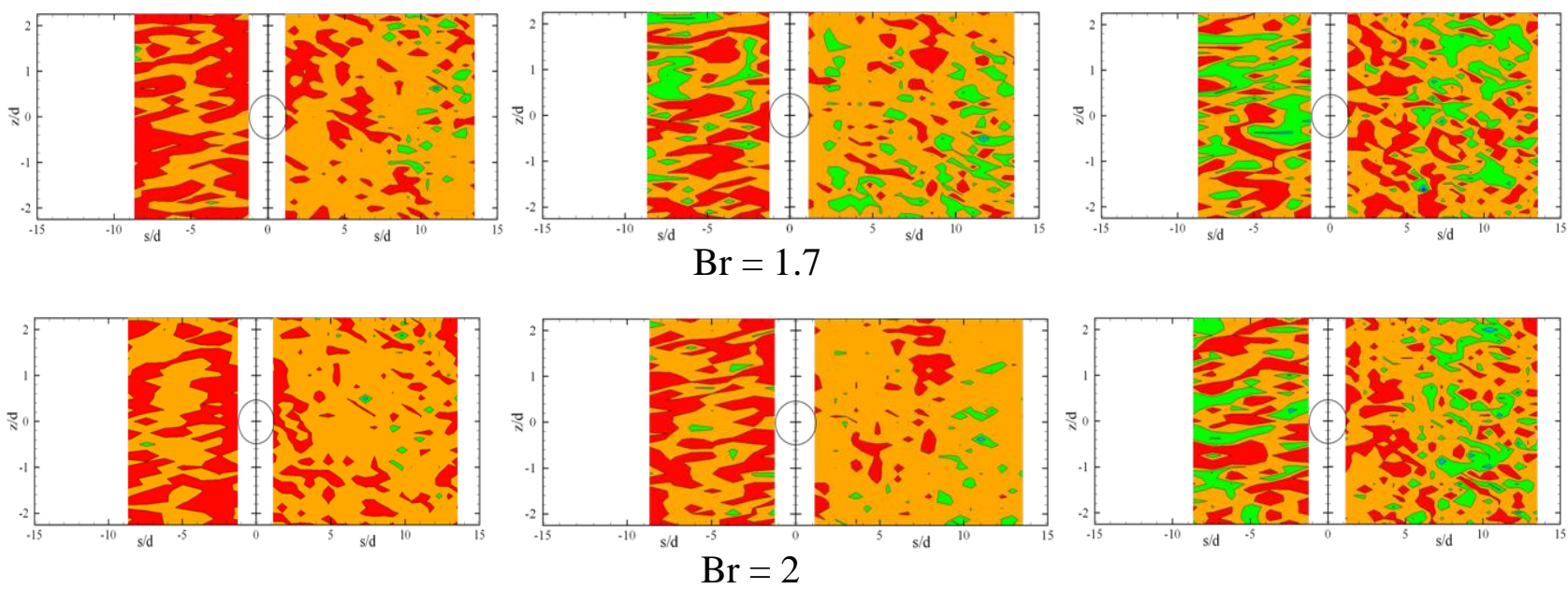

Suction side Pressure side Suction side Pressure side Suction side Pressure side

Figure 3 Local heat transfer coefficient distribution for $60^{\circ}$ inclination angle.

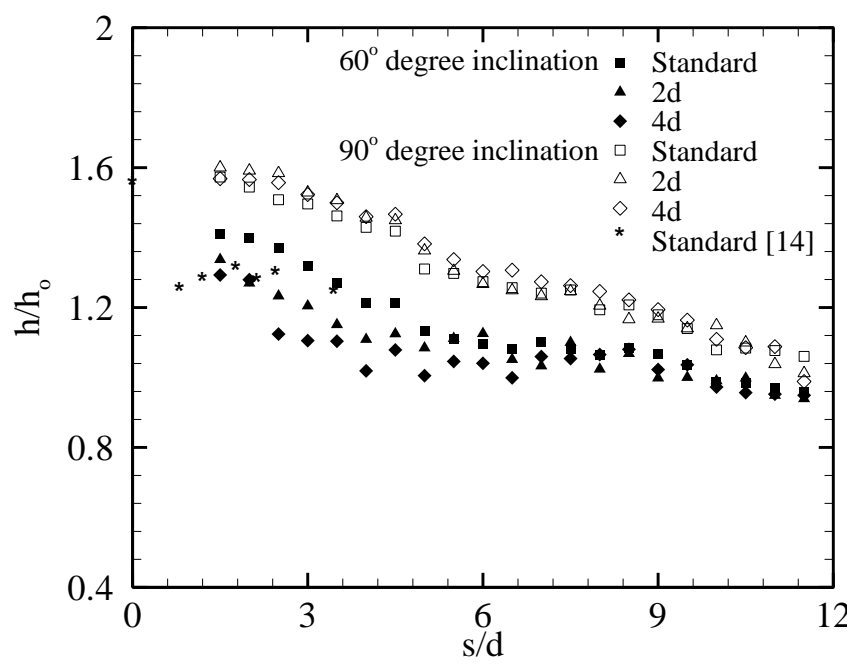

Figure 4. Effect of expansion level on heat transfer coefficient, $\mathrm{Br}=1$ 
Figure 5 presents the effect of the blowing ratio on the heat transfer coefficient at $60^{\circ}$ inclination angle towards the pressure and suction directions downstream the cooling hole. In all cases, the suction side shows lower heat transfer coefficient than the pressure side. The high curvature downstream the cooling hole towards the suction side keeps the coolant away from the vane surface. The unattached coolant causes the disturbances to occur away from the vane surface, causing the lower heat transfer coefficient, and lower effectiveness as seen previously [21]. The cylindrical exit shows insignificant change in the heat transfer coefficient with the blowing ratio in both the pressure and suction sides, as shown in Figure 5a.

By implementing the first expansion level as shown in Figure 5b, the disturbances occurred by the coolant increased due to the undeveloped flow through the short expansion length, causing an in increase the heat transfer coefficient on the pressure side. The flow deviating towards the suction side tends to decrease and a reduction in the heat transfer coefficient is observed. Increasing the blowing ratio causes a slight increase in the heat transfer coefficient downstream the first expansion level on both sides of the vane. The highest expansion level provides the lower heat transfer coefficient due to the further decrease of the jet momentum and the tendency of the flow to remain attached to the vane surface, as shown in Figure 5c. A reduction in the heat transfer coefficient is also observed at the suction side for the highest expansion level compared with the other expansion levels.

Figure 6 presents the effect of the blowing ratio on the heat transfer coefficient at a $90^{\circ}$ inclination angle towards the pressure and suction directions downstream the cooling hole. The overall view of the figure shows the slight effect of the blowing ratio on the HTC. However, the $90^{\circ}$ inclination angle shows higher heat transfer coefficient values compared with the $60^{\circ}$ inclination angle at all expansion levels. The complete confrontation between the coolant and the mainstream induces a high disturbance level that overcomes the expansion of the coolant jet and the subsequent decrease in momentum. For both expansion levels the coolant flow towards the suction side is completely diluted through the mainstream. Therefore, no temperature changes can be traced on the TLC material and no enough data is available on the suction side to be processed.

\section{Net Heat Flux Reduction}

Elnady et al. [21] presents the increase in the effectiveness using the smooth expansion exit with the standard cylindrical hole. In addition, the heat transfer coefficient has been changed by implementing the proposed expansion levels and the inclination angles as well. The increase in the heat transfer coefficient with the film cooling holes provides more thermal stresses on the airfoil surface by increasing the heat load that is transported to the surface. The net heat flux reduction (NHFR) is used to combine the increase of both effectiveness and heat transfer coefficient into one evaluation parameter to conclude the benefit of using the film cooling hole. NHFR can be defined as the ratio between the total heat transferred to the vane surface with film cooling $\left(\mathrm{q}_{\mathrm{f}}\right)$ and the total heat transferred to the vane surface without film cooling $\left(\mathrm{q}_{\mathrm{o}}\right)$. NHFR can be calculated according to equation (9),

$$
N H F R=\frac{q_{f}}{q_{o}}=\left(\frac{h_{f}}{h_{o}}\left(1-\frac{\eta}{\varphi}\right)\right)
$$

where $\phi$ is the overall cooling effectiveness and ranges from 0.5 to 0.7 for a typical airfoil cooling system. The value of $\phi$ is the inverse of $\theta$ which is $f\left(T_{m}, T_{j}\right.$, and $\left.T_{w}\right)$, therefore its value depends on the location on the vane surface, and it can be calculated from equation (10).

$$
\theta=\frac{T_{m}-T_{j}}{T_{m}-T_{w}}
$$


The current study is performed using the transient technique and the temperature of the wall changes during the test duration, therefore the value of $\phi$ is selected to be 0.6 . In the steady state experiments the surface temperature is spatially changed but it is steady with time.
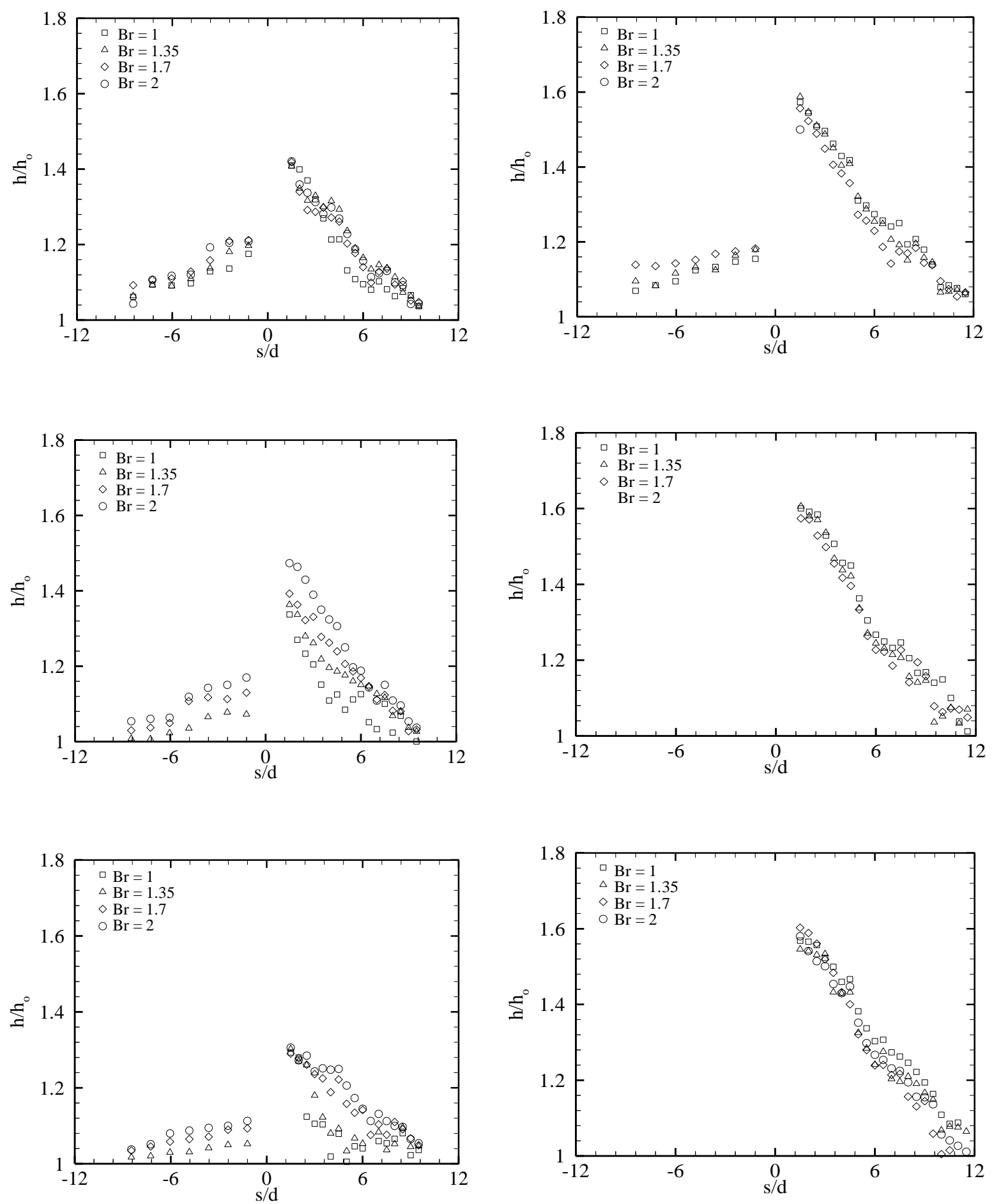

Figure 5. Effect of blowing ratio with $60^{\circ}$ inclination angle

Figure 6. Effect of blowing ratio with $90^{\circ}$ inclination angle
a) cylindrical
b) $2 d$
c) $4 d$
a) cylindrical
b) $2 d$
c) $4 d$ 
Figure 7 presents the averaged spanwise NHFR for different expansion levels at the $60^{\circ}$ inclination angle towards both the suction side and the pressure side at the investigated blowing ratios. The blowing ratio shows insignificant influence on the heat load reduction, while the proposed hole geometry highly improves the cooling performance particularly towards the suction side.

The heat load reduction downstream the standard cylindrical hole is shown on Figure 7a. The cylindrical hole provides moderate effectiveness downstream the cooling hole towards the pressure side with high heat transfer coefficient that shows a high impact on the heat load reduction in that critical region and overcomes the gained effectiveness, keeping the heat load the same as no cooling is applied. Farther downstream, the effectiveness decreases but the heat transfer coefficient decreases with higher rate causing a reduction in the heat load, around 20\% of the load without film cooling. The standard cylindrical hole shows the worst performance just downstream the hole towards the suction side. The effectiveness is low with high heat transfer coefficient that causes an increase in the heat load over that without film cooling. The heat load returns to a normal level later downstream due to the reduction in the heat transfer coefficient.

Figure $7 \mathrm{~b}$ shows the heat load reduction with the first expansion level and reveals the benefit of using the smooth expansion on that critical region of the airfoil. A heat load reduction of about $10 \%$ is gained downstream the hole towards the pressure side with further reduction later downstream. The lowest blowing ratio, $\mathrm{Br}=1$, shows the lowest heat load reduction, while other blowing ratios provide more than $30 \%$ reduction. Another benefit of the smooth expansion is keeping the heat load on the suction side similar to that without film cooling. Figure 7 shows a significant reduction in the heat load using the highest expansion level. Moreover, the heat load is characterized by steady performance over the investigated area while decreasing the difference in heat load between the pressure side and the suction side. The steady heat load, in addition to the similar values downstream the cooling hole in both sides, yields uniform thermal stresses in that critical region of the airfoil and increases the endurance of the protected material.

Figure 8 presents the averaged spanwise NHFR for different expansion levels at the $90^{\circ}$ inclination angle. The direct confrontation between the coolant and the mainstream provides higher heat transfer coefficient compared with that of the $60^{\circ}$ inclination angle. Moreover, the direct contact causes a dissipation of the coolant into the mainstream yielding lower effectiveness. The NHFR accordingly shows the worst heat load achieved in the present study. The standard cylindrical hole shows a significant increase in the heat load, about $40 \%$ as shown in Figure 8a, just downstream of the cooling hole. The over load decreases farther downstream returning to the load seen in the case without film cooling. Implementing the first expansion level with $90^{\circ}$ inclination angle causes a reduction of approximately $10 \%$ in the heat load farther downstream the cooling hole. However, early downstream the direct confrontation and the resultant turbulence keep the over load as high as the standard cylindrical hole, as shown in Figure $8 \mathrm{~b}$. There is no data presented for $\mathrm{Br}=2$ as the coolant has a high momentum, causing a severe jet lift-off, keeping the coolant away from the surface, hence no measurements are sensed by the TLC material.

Applying the second expansion level provides a severe reduction in the jet momentum yielding the coolant at the highest blowing ratio to be attached to the surface. The TLC material can trace the coolant and the measurement can be recorded. The heat load, which is greater than that without film cooling, is still present but slightly lower than in the case of the first expansion level. A lower heat reduction is also gained later downstream as shown in Figure 8c. The $90^{\circ}$ inclination angle shows poor cooling performance even with the smooth expansion and is not recommended to be implemented on the leading edge. 

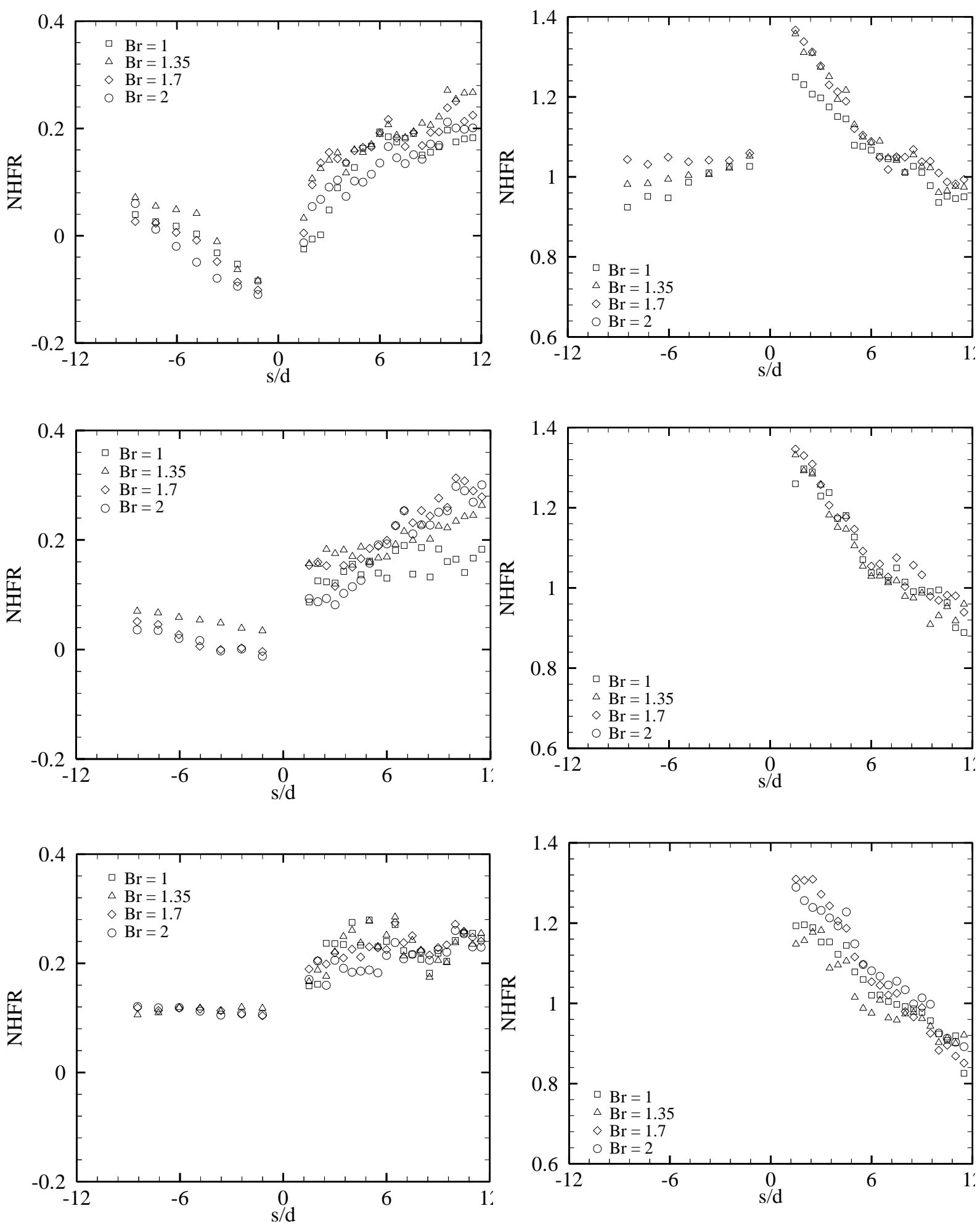

Figure 7. The heat load reduction with $60^{\circ}$ inclination angle
a) cylindrical
b) $2 d$
c) $4 d$

Figure 8 . The heat load reduction with $90^{\circ}$ inclination angle
a) cylindrical
b) $2 d$
c) $4 d$ 


\section{Conclusion}

An experimental investigation has been performed to evaluate the employment of smooth expansion hole positioned at the leading edge of a gas turbine stator. Two expansion levels, $2 \mathrm{~d}$ and $4 \mathrm{~d}$, have been investigated at two inclination angles, $90^{\circ}$ and $60^{\circ}$, in addition to the standard cylindrical hole. The lateral-average cooling effectiveness and normalized heat transfer coefficient have been determined using the transient Thermochromatic Liquid Crystal technique at four different blowing ratios, 1, 1.35, 1.7, and 2. The smooth expansion exit, 2d, shows lower heat transfer coefficient compared with the standard cylindrical exit when supplied with the same coolant flow rate. The high blowing ratios lead to a severe jet lift-off with slight increase in the heat transfer coefficient on the highly curved surface of the leading edge. The magnification of the exit area in the proposed exit, $4 \mathrm{~d}$, causes a significant decrease in the jet momentum and subsequent decreases in the heat transfer coefficient. The suction side shows lower heat transfer coefficient compared with the pressure side in all cases because of the highly curved surface in the suction side which keeps the jet away from the vane surface. The proposed expansion exit provides lower heat transfer coefficient compared with the standard cylindrical exit with insignificant change with the blowing ratio.

The smoother inclination angle, $60^{\circ}$, provides a component of the jet momentum that yields to the main flow and decreases the interaction between both streams. The steep inclination angle, $90^{\circ}$, hardly faces the mainstream, yielding a significant increase in the heat transfer coefficient. The jet momentum in that case completely confronts the mainstream, causing high disturbance hence higher heat transfer coefficient. There is no data presented for same cases especially on the suction side because there is no color traced by the TLC range used. This indicates no effectiveness gained and the heat transfer coefficient changes cannot be predicted. The authors recommend a flow visualization investigation, via PIV, for the same running conditions to reveal the phenomena associated to the flow interaction at this critical region of the airfoil.

\section{References}

[1] Karni, J., and Goldstein, R.J., 1990, "Surface Injection Effect on Mass Transfer From a Cylinder in Crossflow: A Simulation of Film Cooling in the Leading Edge Region of a Turbine Blade," ASME Journal of Turbomachinery, 112(3), pp. 418-427.

[2] Ekkad, S.V. Han, J.C., and Du, H., 1997, "Detailed Film Cooling Measurements on a Cylindrical Leading Edge Model: Effect of Free Stream Turbulence and Coolant Density," ASME paper No. 97-GT-275.

[3] Mick, W.J. and Mayle, R.E., 1988, "Stagnation Film Cooling and Heat Transfer, Including its Effect Within the Hole Pattern," ASME Journal of Turbomachinery, 110(1), pp. 66-72.

[4] Mehendale, A.B., and Han, J.C., 1992, "Influence of High Mainstream Turbulence on Leading Edge Film Cooling Heat Transfer: Effect of Film Hole Spacing,” International Journal of Heat and Mass Transfer, 35(10), pp. 2593-2604.

[5] Ou, S., and Han, J.C., 1992, "Influence of Mainstream Turbulence on Leading Edge Film Cooling Heat Transfer Through Two Rows of Inclined Film Slots," ASME Journal of Turbomachinery, 114(4), pp. 724-733.

[6] Johnston, C.A., Bogard, D.G., McWasters, M.A., 1999, "Highly Turbulent Mainstream Effects on Film Cooling of a Simulated Airfoil Leading Edge," ASME Paper No. 99-GT261.

[7] Hoffs, A., Drost, U., and Bolcs, A., 1997, "Investigation of Effectiveness and Heat Transfer on a Showerhead-Cooled Cylinder," ASME Paper No. 97-GT-69. 
[8] Gritsch, M., Schulz, A., and Witting, S., 2000, "Film-Cooling Holes with Expanded Exits: Near-Hole Heat Transfer Coefficients," International Journal of Heat and Fluid Flow, 21(2), pp. 146-155.

[9] Bell, C.M., Hamakawa, H., and Ligrani, P.M., 2000, "Film Cooling from Shaped Holes," ASME Journal of Heat Transfer, 122(2), pp. 224-232.

[10] Cho, H. H., Rhee, D.H, and Kim, B.G., 2001, "Enhancement of Film Cooling Performance Using a Shaped Film Cooling Hole with Compound Angle Injection," JSME International Journal, Series B, 44(1), pp. 99-110.

[11] Yu, Y., Yen, C.H., Shih, T.I., Chyu, M.K., and Gogineni, S., 2002, "Film Cooling Effectiveness and Heat Transfer Coefficient Distributions Around Diffusion Shaped Holes," ASME Journal of Heat Transfer, 124(5), pp. 820-827.

[12] Reiss, H., and Bolcs, A., 2000, "Experimental Study of Showerhead Cooling on a Cylinder Comparing Several Configurations Using Cylindrical and Shaped Holes," ASME Journal of Turbomachinery, 122(1), pp. 161-169.

[13] York, W.D. and Leylek, J.H., 2002, "Leading-Edge Film-Cooling Physics - Part II: Heat Transfer Coefficient," ASME Paper No. 2002-GT-30167.

[14] Lu, Y., Allison, D., and Ekkad, S.V., 2007, "Turbine Blade Showerhead Film Cooling: Influence of Hole Angle and Shaping," International Journal of Heat and Fluid Flow, 28(5), pp. 922-931.

[15] Islami, S.B., Tabrizi, A., Jubran, B., and Esmaeilzadeh, E., 2010, "Influence of Trenched Shaped Holes on Turbine Blade Leading Edge Film Cooling," Heat Transfer Engineering, 31(10), pp. 889-906.

[16] Elnady, T., Hassan, I., Kadem, L., and Lucas, T., 2011, "Experimental Investigation of Double Rows Film Cooling on Vane Pressure Side," ASME Paper No. IMECE201162007.

[17] Vedula, R.J., Metzger, D.E., 1991, "A Method for the Simultaneous Determination of Local Effectiveness and Heat Transfer Distributions in Three-Temperature Convection Situations," ASME Paper No. 91-GT-345.

[18] Ekkad, S.V., Ou, S., and Rivir, R.B., 2004, "A Transient Infrared Thermography Method for Simultaneous Film Cooling Effectiveness and Heat Transfer Coefficient Measurements from a Single Test," ASME Journal of Turbomachinery, 126(4), pp. 597603

[19] Kline, S. J., and McClintock, F. A., 1953, "Describing Uncertainties in Single-Sample Experiments," ASME Mechanical Engineering, 75, pp. 3-8.

[20] Moffat, R. J., 1988, "Describing the Uncertainties in Experimental Results"; Experimental Thermal and Fluid Science, 1(1), pp. 3-17

[21] Elnady, T., Hassan, I., Kadem, L., and Lucas, T., 2010, "Experimental Investigation of Film Cooling Effectivenes for a New Shaped Hole at the Leading Edge," ASME Paper No. IMECE2010-38373. 